\title{
AUTHOR INDEX FOR VOLUME 100
}

ACCIARRI, C. and LUCCHINI, A.; The generating graph of infinite abelian groups

AKHLAGHI, Z.; see SAYANJALI, Z.

ARIKATLA, S. R.; see KOLEY, B.

ARNOLD, L. and LE MERDY, C.; New counterexamples on Ritt operators, sectorial operators and $R$-boundedness

BAIER, S., LYNCH, S. B. and ZHAO, L.; A lower bound for the large sieve with square moduli

BARNSLEY, M. F. and MIHALACHE, N.; Symmetric itinerary sets

BAU, S. and LEI, Y.; Bisectors in vector groups over integers

BAYATI, S., JAHANI, I. and TAGHIPOUR, N.; Linear quotients and multigraded shifts of Borel ideals

BHAVE, A. and BORA, L.; On the Selmer group of a certain $p$-adic Lie extension

BORA, L.; see BHAVE, A.

BREUER, F.; Periods of Ducci sequences and odd solutions to a Pellian equation

CAMERON, K., HUANG, S. and MERKEL, O.; A bound for the chromatic number of $\left(P_{5}\right.$, gem)-free graphs

CASELLA, A.; Branched Cauchy-Riemann structures on once-punctured torus bundles

CHEN, C., KERR, B. and MOHAMMADI, A.; A new sum-product estimate in prime fields

CHEN, F.; see LIN, J.

CHEN, G.; Estimates of the second derivative of bounded analytic functions

CHEN, X. and LEWIS, M. L.; Monolithic Brauer characters

CHEN, X. and LEWIS, M. L.; Squares of degrees of Brauer characters and monomial Brauer characters

CHERN, S.; Note on sums involving the Euler function

CHO, N. E., KOWALCZYK, B. and LECKO, A.; Sharp bounds of some coefficient functionals over the class of functions convex in the direction of the imaginary axis

DE MELO, E. and SHUMYATSKY, P.; Fitting subgroup and nilpotent residual of fixed points

DHARMADASA, H. K. and MORAN, W.; A generalisation of the Frobenius reciprocity theorem

DING, Y. and SUN, Y.-C.; A note on the sum of reciprocals

DOUST, I.; A note on positive $\mathcal{A N}$ operators

DRAGOMIR, S. S.; Lipschitz-type inequalities for analytic functions in Banach algebras

EAST, J. and NILES, R.; Integer polygons of given perimeter 
FAN, L.; see GENG, X.

GENG, X., FAN, L. and MA, X.; Diameter of commuting graphs of symplectic algebras

GHADERMARZI, A.; On the factorisation of $x^{2}+D$

GONZÁLEZ, A. and LÓPEZ-LÓPEZ, J. L.; Spaces of special quadrilaterals

HADWIN, D., LI, W., LIU, W. and SHEN, J.; A characterisation of tracially nuclear $\mathrm{C}^{*}$-algebras

HARDING, B.; Symmetric itinerary sets: algorithms and nonlinear examples

HAYTHORPE, M. and NEWCOMBE, A.; On the crossing number of the Cartesian product of a sunlet graph and a star graph

HUANG, S.; see CAMERON, K.

JAHANI, I.; see BAYATI, S.

JONES, L.; A brief note on some infinite families of monogenic polynomials

KANEKO, M., OYAMA, K. and SAITO, S.; Analogues of the Aoki-Ohno and Le-Murakami relations for finite multiple zeta values

239

KERR, B.; see CHEN, C.

KHOI, V. T.; On the probability distribution of the product of powers of elements in compact Lie groups

KHOSRAVI, B.; see SAYANJALI, Z.

440

428

KOLEY, B. and ARIKATLA, S. R.; Cyclotomic factors of Borwein polynomials KOWALCZYK, B.; see CHO, N. E.

41

KRYCZKA, A.; A quantitative extension of Szlenk's theorem

LAOHAKOSOL, V.; see PONPETCH, K.

338

LATERVEER, R.; A remark on the Chow ring of Küchle fourfolds of type $d 3$
LÊ, Q. T., NGUYEN, L. P. H. and PHO, D. T.; On complex homogeneous singularities

304

410

LE MERDY, C.; see ARNOLD, L.

LECKO, A.; see CHO, N. E.

498

LEI, Y.; see BAU, S.

LEWIS, M. L.; see CHEN, X.

434

LEWIS, M. L.; see CHEN, X.

LI, W.; see HADWIN, D.

LIN, J., ZENG, Q. and CHEN, F.; Maximum cuts in graphs without wheels 13

LIU, K. and YU, P.; A note on the periodicity of entire functions 290

LIU, W.; see HADWIN, D.

LOO, S. L.; Mathematical modelling of the evolution of human behaviours and strategic choice

LÓPEZ-LÓPEZ, J. L.; see GONZÁLEZ, A.

LOXTON, J. H.; Editorial: A centenary of the Bulletin of the Australian Mathematical Society

LU, K. W.; Weak subordination of multivariate Lévy processes 518

LUCCHINI, A.; see ACCIARRI, C.

LYNCH, S. B.; see BAIER, S. 225 
MA, X.; see GENG, X.

MAHMOODI, A.; see ZIAMANESH, $M$.

MASTROSTEFANO, D.; Positive proportion of short intervals containing a prescribed number of primes

MAVECHA, S.; see PONPETCH, K.

MCCULLOUGH, M. H.; Nonlinear time series analysis using ordinal networks with select applications in biomedical signal processing

MERKEL, O.; see CAMERON, K.

MIHALACHE, N.; see BARNSLEY, M. F.

MOHAMMADI, A.; see CHEN, C.

MOHAPATRA, M. R., WANG, X. and ZHU, J.-F.; Boundary Schwarz lemma for solutions to nonhomogeneous biharmonic equations

MONETTA, C. and TORTORA, A.; A nilpotency criterion for some verbal subgroups

MORAN, W.; see DHARMADASA, H. K.

MOREE, P. and SHA, M.; Primes in arithmetic progressions and nonprimitive roots

MORRIS, S. A.; A remark on the separable quotient problem for topological groups

NEWCOMBE, A.; see HAYTHORPE, M.

NGUYEN, H. B. Q.; see TRAN, K. T.

NGUYEN, L. P. H.; see LÊ, Q. T.

NILES, R.; see EAST, J.

NOLAN, M.; Geometry of integrable lattice equations and their reductions $\quad 168$

OYAMA, K.; see KANEKO, M.

PAWLAK, R. J. and POPRAWA, J.; On generators and disturbances of dynamical systems in the context of chaotic points

PHO, D. T.; see LÊ, Q. T.

PONPETCH, K., LAOHAKOSOL, V. and MAVECHA, S.; A system of functional equations satisfied by components of a quadratic function and its stability

POPRAWA, J.; see PAWLAK, R. J.

PRABHU, N.; see RAM MURTY, M.

PRASAD, R.; Streamflow and soil moisture forecasting with hybrid data intelligent machine learning approaches: case studies in the Australian Murray-Darling basin

RAM MURTY, M. and PRABHU, N.; The error term in the Sato-Tate theorem of Birch

REIS, L.; On the dimension of permutation vector spaces

SAITO, S.; see KANEKO, M.

SANDERS, T.; Schur's colouring theorem for noncommuting pairs

SAYANJALI, Z., AKHLAGHI, Z. and KHOSRAVI, B.; On the regularity of character degree graphs 
SHA, M.; see MOREE, P. $\quad 388$

SHEN, J.; see HADWIN, D. 119

SHOJAEE, B.; see ZIAMANESH, M. $\quad 479$

SHULMAN, T. and UUYE, O.; Approximations of subhomogeneous algebras 328

SHUMYATSKY, P.; see DE MELO, E. $\quad 61$

SINGH, S. and ZELENYUK, Y.; Alternating colourings of the vertices of a regular polygon

STEINERBERGER, S.; A compactness principle for maximising smooth functions over toroidal geodesics

148

$\begin{array}{lr}\text { SUN, Y.-C.; see DING, Y. } & 189 \\ \text { TAGHIPOUR, N.; see BAYATI, S. } & 48\end{array}$

TANG, D.; Vanishing coefficients in four quotients of infinite product expansions

TIAN, L.; see WANG, Y.

323

TORTORA, A.; see MONETTA, C. 281

TRA, K. Q.; see TRAN, K. T.

344

TRAN, K. T., TRAN, L. N., NGUYEN, H. B. Q. and TRA, K. Q.; Recovery of the temperature distribution in a multilayer fractional diffusion equation

TRAN, L. N.; see TRAN, K. T.

344

344

UUYE, O.; see SHULMAN, T.

328

WANG, L.-Y. and WU, H.-L.; Applications of Lerch's theorem to permutations of quadratic residues

362

WANG, X.; see MOHAPATRA, M. R.

470

WANG, Y. and TIAN, L.; A note on radial symmetry for an integral equation of Wolff type

323

WATSON, N. A.; Extendable temperatures $\quad 297$

WU, H.-L.; see WANG, L.-Y.

YU, P.; see LIU, K. $\quad 290$

ZAPATA, C. A. I.; Category and topological complexity of the configuration space $F\left(G \times \mathbb{R}^{n}, 2\right)$

ZELENYUK, Y.; see SINGH, S.

ZENG, Q.; see LIN, J.

ZHANG, Y.; A note on matrix approximation in the theory of multiplicative Diophantine approximation

ZHAO, L.; see BAIER, S.

ZHOU, N. H.; On the distribution of the rank statistic for strongly concave compositions

ZIAMANESH, M., SHOJAEE, B. and MAHMOODI, A.; Essential amenability of dual Banach algebras 


\section{INFORMATION FOR AUTHORS}

The Bulletin of the Australian Mathematical Society aims at quick publication of original research in all branches of mathematics. To ensure speedy publication, only articles which are sufficiently well presented, able to be published without revision, and which are judged by the Editor (often in consultation with an Associate Editor) to be competitive are refereed. This policy is in the interests of authors, as a quick rejection is better than a slow rejection. The Bulletin receives more than five times the material that can be published, therefore there are many commendable papers not accepted. Editorial decisions on acceptance or otherwise are taken quickly, normally within a month of receipt of the paper. Papers are accepted only after peer review.

Manuscripts are accepted for review with the understanding that the same work is not concurrently submitted elsewhere. For a paper to be acceptable for publication, not only should it contain new and interesting results, but also

(i) the exposition should be clear and attractive, and

(ii) the manuscript should be in publishable form, without revision.

Further information regarding these requirements may be found through our website www.austms.org.au/Bulletin. Authors are asked to avoid, as far as possible, the use of mathematical symbols in the title.

Articles should be prepared in $\mathrm{ET}_{\mathrm{E}} \mathrm{X}$ using $\mathcal{A}_{\mathcal{M}} \mathcal{S}$-LTEX packages and submitted as a PDF file via our journal management system, at www.austms.org.au/Publications/Submissions/BAustMS. This permits authors to track their papers through the editorial process. Recent versions of $\mathrm{T}_{\mathrm{E}} \mathrm{X}$ are able to produce PDF files directly. A LTTEX class file for the Bulletin can be downloaded from the website. Authors who need assistance may email the secretary of the Bulletin at editor@bulletin.austms.org.au.

Authors are advised to keep copies of all files of the submitted article; the Bulletin will not accept responsibility for any loss.

\section{EDITORIAL POLICY}

1. References. Arrange references alphabetically (by surname of the first author) and cite them numerically in the text. Ensure the accuracy of the references: authors' names should appear as in the work quoted. Include in the list of references only those works cited, and avoid citing works which are in preparation or submitted. Where the work cited is not readily accessible (for example, a preprint) a copy of the article should be included with your submission.

\section{Abstracts.}

1. Each paper must include an abstract of not more than 150 words, which should contain a brief but informative summary of the contents of the paper, but no inessential details.

2. The abstract should be self-contained, but may refer to the title.

3. Specific references (by number) to a section, proposition, equation or bibliographical item should be avoided.

3. Subject Classification and Key Words. Authors should include a few key words and phrases and one or more classification numbers, following the American Mathematical Society 2010 Mathematics Subject Classification for all codes. Details of this scheme can be found on the web at www.ams.org/msc.

4. Abstracts of PhD Theses. The Bulletin endeavours to publish abstracts of all accepted Australasian $\mathrm{PhD}$ theses in mathematics. One restriction, however, is that the abstract must be received by the Editor within six months of the degree being approved.

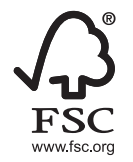

This journal issue has been printed on FSC-certified paper and cover board. FSC is an independent, non-governmental, not-for-profit organisation established to promote the responsible management of the world's forests. Please see www.fsc.org for information. 


\section{Table of Contents}

Bisectors in vector groups over integers

Bau, S. \& Lei, $Y$.

Applications of Lerch's theorem to permutations of quadratic residues

Wang, L. $Y$. \& $W u, H .-L$.

A note on matrix approximation in the theory of multiplicative Diophantine approximation

Zhang, $Y$.

Positive proportion of short intervals containing a prescribed number of primes

Mastrostefano, $D$.

Primes in arithmetic progressions and nonprimitive roots

Moree, P. \& Sha, $M$.

On complex homogeneous singularities

Lê, Q. T., Nguyen, L. P. H. \& Pho, D. T.

A remark on the Chow ring of Küchle fourfolds of type $d \mathbf{3}$

Laterveer, $R$

Diameter of commuting graphs of symplectic algebras

Geng, X., Fan, L. E Ma, X.

On the regularity of character degree graphs

Sayanjali, Z., Akhlaghi, Z. E Khosravi, B.

Monolithic Brauer characters

Chen, X. E Lewis, M. L.

On the probability distribution of the product of powers of elements in compact Lie groups Khoi, V.T.

Schur's colouring theorem for noncommuting pairs

Sanders, T.

A remark on the separable quotient problem for topological groups

Morris, S. A.

Estimates of the second derivative of bounded analytic functions

Chen, $G$.

Boundary Schwarz lemma for solutions to nonhomogeneous biharmonic equations

Mohapatra, M. R., Wang, X. E Zhu, J.-F.

Essential amenability of dual Banach algebras

Ziamanesh, M., Shojaee, B. \& Mahmoodi, A.

Lipschitz-type inequalities for analytic functions in Banach algebras

Dragomir, S. S.

New counterexamples on Ritt operators, sectorial operators and $\boldsymbol{R}$-boundedness

Arnold, L. Ë Le Merdy, C.

Gategory and topological complexity of the configuration space $F\left(G \times \mathbb{R}^{n}, 2\right)$

Zapata, C.A.I.

Abstracts of $\mathrm{PhD}$ Theses

Weak subordination of multivariate Lévy processes

Lu, K. W.

Streamflow and soil moisture forecasting with hybrid data intelligent machine learning approaches: case studies in the Australian Murray-Darling basin

Prasad, $R$.

Mathematical modelling of the evolution of human behaviours and strategic choice

Loo, S. L.

Author Index for Volume 100 